\title{
Experiências de sofrimento psíquico em estudantes de graduação do curso de
}

\section{Engenharia}

\author{
Experiences of psychic suffering in undergraduate of the Engineering course \\ Experiencias de sufrimento psquico en estudiantes de pregrado del curso de Ingeiaria
}

Recebido: 28/01/2022 | Revisado: 02/02/2022 | Aceito: 13/02/2022 | Publicado: 18/02/2022

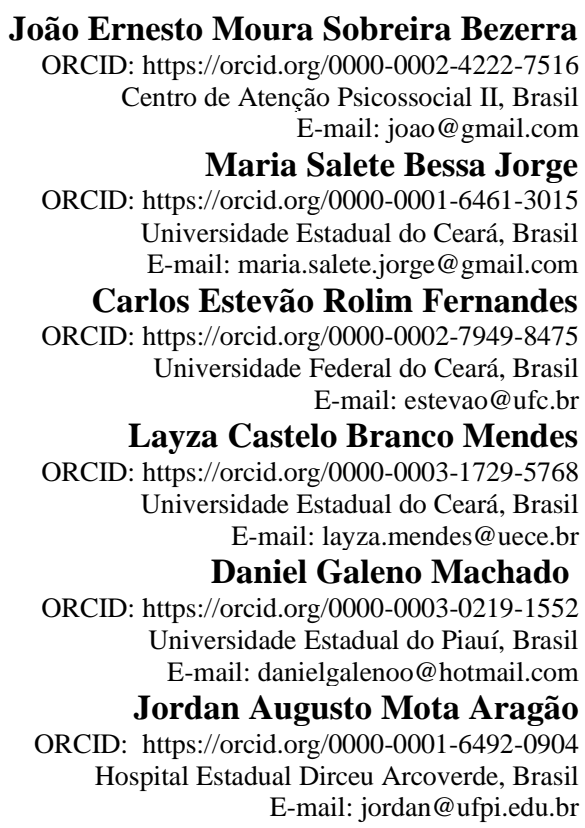

\begin{abstract}
Resumo
Objetivo: Compreender, com base nas narrativas, as experiências de sofrimento psíquico vivenciadas pelos estudantes do Centro de Tecnologia da Universidade Federal do Ceará. Método: Trata-se de uma pesquisa de abordagem qualitativa e de cunho exploratório e descritivo, realizada nos 11 cursos de graduação de Engenharia do Centro de Tecnologia da Universidade Federal do Ceará. Foram realizadas entrevistas semiestruturadas e constituído um grupo focal. As narrativas foram organizadas em nós e analisadas tendo como base a análise do discurso de Bardin. Resultados: Foram formadas 4 categorias com suporte nos dez nós considerados na análise dos discursos: Categoria 1: "notas", "reprovação" e "estresse"; Categoria 2: "ensino" e "relação com professor"; Categoria 3: "saúde mental", "desistência", "suporte" e "suporte externo"; e Categoria 4: "ser estudante de engenharia". Conclusão: São necessárias propostas de intervenções preventivas, de identificação e cuidado ao sofrimento psíquico destes alunos, a fim de promover saúde mental e qualidade de vida discente.
\end{abstract}

Palavras-chave: Saúde mental; Serviços de saúde para estudantes; Tecnologia.

\begin{abstract}
Objective: To understand, based on narratives, the experiences of psychic suffering experienced by students at the Technology Center at the Federal University of Ceará. Method: This is a research with a qualitative approach and an exploratory and descriptive nature, carried out in eleven undergraduate courses in Engineering at the Technology Center of the Federal University of Ceará. Semi-structured interviews were carried out and a focus group was constituted. The narratives were organized in knots and analyzed based on Bardin's discourse analysis. Results: 4 categories were formed from the ten nodes considered in the discourse analysis: Category 1: "grades", "failure" and "stress"; Category 2: "teaching" and "relationship with teacher"; Category 3: "mental health", "dropout", "support" and "external support"; and Category 4: "being an engineering student". Conclusion: It is necessary to propose preventive interventions, identification and care for the psychological distress of these students, in order to promote mental health and quality of life for students.
\end{abstract}

Keywords: Mental health; Student health services; technology. 


\begin{abstract}
Resumen
Objetivo: Comprender, a partir de narrativas, las vivencias de sufrimiento psíquico vividas por estudiantes del Centro Tecnológico de la Universidad Federal de Ceará. Método: Se trata de una investigación con enfoque cualitativo y de carácter exploratorio y descriptivo, realizada en once cursos de pregrado en Ingeniería en el Centro Tecnológico de la Universidad Federal de Ceará. Se realizaron entrevistas semiestructuradas y se constituyó un grupo focal. Las narrativas se organizaron en nudos y se analizaron a partir del análisis del discurso de Bardin. Resultados: se formaron 4 categorías a partir de los diez nodos considerados en el análisis del discurso: Categoría 1: "calificaciones", "reprobación" y "estrés"; Categoría 2: "enseñanza" y "relación con el maestro"; Categoría 3: "salud mental", "abandono", "apoyo" y "apoyo externo"; y Categoría 4: "ser estudiante de ingeniería”. Conclusión: Es necesario proponer intervenciones preventivas, identificación y atención al malestar psicológico de estos estudiantes, con el fin de promover la salud mental y la calidad de vida de los estudiantes.
\end{abstract}

Palabras clave: Salud mental; Servicios de salud para estudiantes; Tecnología.

\title{
1. Introdução
}

As experiências do período acadêmico são importantíssimas para a construção dos alunos, pois futuramente se espera que, por meio do exercício de suas profissões, possam transformar realidades em nosso País. Entretanto, os estudantes são confrontados rotineiramente com exigências exacerbadas acerca da qualificação profissional.

Apreende-se, ainda, que os universitários, em sua maioria, são adolescentes ou adultos jovens ainda em processo de construção de sua identidade e, portanto, possuem vulnerabilidade psíquica própria desse momento do desenvolvimento humano, que, somadas às cobranças relativas à vida estudantil de nível superior, que exige maior autonomia e responsabilidade, podem desencadear sofrimento psíquico (Bertol \& Souza, 2010).

Lobato (2004) enfatizou que se vive uma contemporaneidade composta de cenários provisórios no mundo do trabalho, e os adolescentes e adultos jovens estão inseridos nesse contexto que, por si só, é ansiogênico, ou seja, promotor de ansiedade excessiva.

De acordo com Silveira et al. (2011), há aumento da prevalência e da gravidade das perturbações psiquiátricas na população dos estudantes universitários. A faixa etária da maioria dos estudantes universitários é um período do desenvolvimento em que surgem muitas vezes adoecimentos mentais graves.

Com efeito, nas universidades, aos estudantes que apresentam dificuldades e adoecimento emocional no decorrer de sua trajetória acadêmica, deveriam existir programas de apoio psicológico que dessem suporte para reduzir o estresse, o que possibilitaria diminuir a prevalência e a incidência de sintomatologias depressivas e ansiosas, e ideações e tentativas de suicídio. Ademais, tais medidas minimizariam dificuldades de relacionamento entre alunos, entre professores e entre alunos e professores. (Moro et al., 2005).

Existem universidades públicas e privadas que têm programas de acompanhamento a alunos com sofrimento psíquico como o Observatório estudantil, criado na UFBA (Sampaio, 2011), entre outros (Assis \& Oliveira, 2010). Outras têm ações isoladas para estudantes que já se encontram em processo de intenso sofrimento. Porém, na maioria das vezes, não existe nem mesmo as atitudes isoladas, muito menos programas de cuidados com a saúde mental, com a prevenção de adoecimento ou com a promoção da saúde integral, que inclui a psíquica.

Justifica-se a necessidade de ações de prevenção e promoção em saúde psicossocial do corpo discente de IES por razão do contexto sociocultural, em que esses sujeitos vivem, incluindo as grandes metrópoles. Ressalta-se que morar em grandes cidades implica em se submeter a diversas condições que acarretam à menor capacidade de manutenção da saúde psicossocial, como: a percorrer grandes distâncias, diminuir o convívio familiar, suprimir tempo de lazer e cuidados físicos. Além disso, as incertezas relativas ao mundo acadêmico competitivo e individualista gera sofrimento psíquico (Flach, 2009).

Cuidar da saúde psicossocial não significa cuidar do adoecimento psicopatológico, a dicotomia saúde-doença hoje é suprida pela ideia de saúde-doença-cuidado como processo de cuidado integral (Almeida Filho, 2008). Abordar a demanda de sofrimento psíquico das pessoas que compõem a comunidade acadêmica traz o conhecimento do bem estar psicossocial. 
Identificar alguém com transtorno psíquico, antes de um prejuízo psicossocial e clínico maior, é premente para sua recuperação mais rápida e consistente.

Os alunos precisam ter conhecimento sobre as necessidades de preservação da saúde mental de seus pares e da sociedade. Além disso, os êxitos em suas habilidades de estudo e em sua formação são proporcionais às suas condições de saúde mental. De mesmo modo, a universidade obtém melhores resultados científicos e de formação de profissionais quando seus alunos, professores e servidores estão bem psiquicamente. Assim, concorda-se com Sousa e Marques (2010), acerca da necessidade de os atuais projetos pedagógicos de curso, junto às suas coordenações de graduação e pós-graduação necessitam ter espaço para contemplar cuidados com o bem-estar biopsicossocial.

Distintas pesquisas acerca de universitários focaram questões relacionadas à saúde mental e ao sofrimento psíquico, e, outras enfatizaram aspectos gerais da qualidade de vida. (Sousa et al., 2013). Porém, a maioria delas foi realizada com estudantes de áreas da saúde. Imagina-se que a concentração de estudos dessa natureza na área da saúde se justifica pela aproximação dos pesquisadores às questões de saúde mental relacionadas à qualidade de vida e/ou sofrimento psíquico.

Poucos são os estudos que se detiveram a analisar sofrimento psíquico e sintomas que comprometem a saúde mental em estudantes de engenharia. Acredita-se que pelo fato de não haver, na formação em engenharia, nenhuma aproximação com as áreas da saúde (principalmente da saúde mental), estando alunos e professores distantes desse tema, percebendo-o apenas quando vivenciado por meio do próprio adoecimento (Castro, 2017).

Estudos na área da engenharia, bem como nas áreas de saúde, concluem que não há apenas um fator isolado que desencadeia adoecimento mental e tais adoecimentos prejudicam a aprendizagem. Logo, conclui-se que são necessárias as universidades reconhecerem a existência desses adoecimentos e realizarem atividades de cuidado (Castro, 2007).

Com efeito, objetiva-se nesta pesquisa compreender, com base nas narrativas, as experiências de sofrimento psíquico vivenciadas pelos estudantes do Centro de Tecnologia da Universidade Federal do Ceará (CT - UFC).

\section{Metodologia}

Trata-se de uma pesquisa de abordagem qualitativa e de cunho exploratório e descritivo. A importância da abordagem qualitativa na pesquisa encontra-se na busca de sentidos e significações nas ações e nas narrativas dos sujeitos pesquisados. A pesquisa exploratória objetiva explorar aspectos de uma situação não conhecida, para obter maiores informações sobre determinado objetivo, e a descritiva objetiva, identificar e descrever as características de um determinado fenômeno. A metodologia qualitativa concorda com Minayo (1993), visto que se trata de uma abordagem subjetiva, afirmada com o universo de significados, crenças, valores, entre outros.

O campo de pesquisa foi 11 cursos de Graduação de Engenharia, que compõem o Centro de Tecnologia, da Universidade Federal do Ceará (CT-UFC). Os dados foram coletados por meio do Grupo Focal, que segundo Pope e Mays (2000) se configura como uma modalidade de entrevistas com grupos, baseada na comunicação e na interação. Os sujeitos pesquisados foram seis estudantes entrevistados individualmente e participaram 12 estudantes do grupo focal. Foi realizada a técnica de entrevista semiestruturada, que versou sobre as questões de experiências da vida universitária, conflitos, sofrimento psíquico e suporte percebido. Os sujeitos, para essa parte da pesquisa, foram convidados entre estudantes de outros semestres, exceto do primeiro.

Além disso, também foi constituído um grupo focal formado por estudantes de semestres diversos. Apenas alunos do primeiro semestre foram excluídos. Tanto para os entrevistados individualmente quanto os participantes do grupo focal foram selecionados por meio do envio de convite, via correio eletrônico, para uma percentagem dos alunos, escolhidos aleatoriamente, dos 11 cursos de engenharia. Essa percentagem foi baseada na quantidade de alunos de cada curso. 
As entrevistas foram registradas e gravadas em aparelho gravador, e, posteriormente, transcritas ipsis litteris pelo autor da pesquisa. As perguntas de partida feitas aos alunos nas entrevistas individuais foram duas: $1^{\text {a }}$ ) Fale sobre sua saúde mental, e como se relaciona com a faculdade que você cursa; $2^{\mathrm{a}}$ ) Fale sobre o suporte que você recebe durante o curso. Para o grupo focal, os assuntos lançados aos participantes foram pautados nos nós obtidos com as transcrições das entrevistas individuais no NVivo 10. Lançou-se os nós, um a um, aos estudantes reunidos no grupo e eles iam comentando suas percepções e opiniões.

Os questionários foram analisados utilizando o software GNU Octave. As narrativas foram analisadas tendo como base a análise do discurso por meio da utilização do software NVivo versão 10. Os resultados dos questionários foram apresentados em forma de figuras, os quais foram descritos e interpretados à luz da literatura pertinente.

Os resultados das entrevistas e do grupo focal foram inseridos no NVivo 10 e organizados em nós, com criação de códigos e separação das falas por cada nó, com a finalidade de iniciar o processo de análise de Bardin em suas três fases. (Bardin, 2010).

No NVivo 10, sempre que um fragmento de texto é codificado, uma referência a esse fragmento fica armazenada em um ou mais nós, a critério do pesquisador e conforme o referencial teórico adotado para a análise de conteúdo. Os nós podem representar categorias de análise previamente definidas ou criadas durante o processo de análise. (Lage, 2011). Nesta pesquisa, foram criados dez nós referentes à intercessão dos assuntos abordados pelos sujeitos da pesquisa e representados em quatro categorias.

$\mathrm{Na}$ busca por tratar mais sistematicamente o material, escolheu-se utilizar o software QSR (Qualitative Solutions Research) NVivo® versão 10 descrito como NVivo 10. Entre as principais estruturas deste software estão os Nós, que podem ser caracterizados como uma estrutura para armazenamento de informações codificadas e pode assumir significados diferentes, dependendo da abordagem metodológica utilizada na pesquisa. Se essas categorias tiverem subcategorias, então será utilizada uma estrutura de árvore de nós. (Lage, 2011).

A pesquisa foi realizada considerando-se as indicações contidas na Resolução nº 466/2012 do Conselho Nacional de Saúde do Ministério da Saúde do Brasil, acatando-se os aspectos éticos de uma pesquisa com seres humanos, sob o número do parecer do Conselho de Ética e Pesquisa 90227818.1.0000.5534. Entre as indicações, respeitou-se os aspectos tais como o anonimato e a utilização do Termo de Consentimento Livre e Esclarecido (TCLE), para os estudantes universitários dos CTUFC no sentido de resguardarem-se os sujeitos da pesquisa. (Brasil, 2012).

\section{Resultados e Discussão}

Foram entrevistados seis estudantes de engenharia, sendo três homens e três mulheres. Do grupo focal, participaram 12 alunos, dos quais cinco eram homens e sete mulheres.

Os problemas de saúde mental podem atingir aspectos diversos da vida do estudante universitário, incluindo o bemestar acadêmico, mas, também físico, emocional e social, além de levar a quadros graves que podem gerar comportamentos suicidas. (Nogueira, 2017).

Nesta pesquisa, destacou-se alguns determinantes de adoecimento e sofrimento por parte dos estudantes de engenharia, conforme as categorias descritas a seguir. As categorias foram formadas pelos dez nós considerados na análise dos discursos. A categoria 1 foi formada pelos nós "notas", "reprovação" e "estresse"; a categoria 2, pelos nós "ensino" e "relação com professor"; a categoria 3, pelos nós "saúde mental", "desistência", "suporte" e "suporte externo"; e a categoria 4, pelo nó "ser estudante de engenharia". 


\section{Categoria 1 - Notas, reprovação e estresse}

Nogueira descreveu a revisão de literatura de Storrie, Ahern e Tuckett sobre a saúde mental dos estudantes universitários, que confirma os problemas dessa população relacionados com ansiedade, estresse, sintomas depressivos, dificuldades de integração e relação interpessoais e não progressão acadêmica. (Nogueira, 2017).

Os estudantes revelaram o estresse por que passam na faculdade, sob alguns aspectos. Primeiro, tratam da cobrança que sofrem: “é uma cobrança sem foco que existe na faculdade; fala-se de pressão da família também: tenho um amigo que a família pressiona pra tirar dez; e do próprio aluno sobre si: há acúmulo de muita cobrança, da família e de você mesmo".

Períodos de provas também colaboram para o estresse:

O período pré-prova sempre há muita ansiedade; os alunos preocupados com prazo de prova, prazo de trabalhos, falavam pra ele (professor), e ele fazia isso com brincadeira, com um sorriso irônico; você fica sem chão, tentando estudar porque a quantidade de conteúdo é imensa; e que intensifica no final de semestre.

Outra faceta do estresse é chamada por dois alunos como abuso:

Eu particularmente não sofri muito abuso moral, mas eu já convivi com colegas que falaram disso, que fizeram terapia por causa disso; ela (o aluno está se referindo a uma colega) se sentia cansada o tempo todo, se sentia deprimida, sofria abuso dos professores, abuso moral, acho que ela já sofreu até abuso sexual por parte dos professores.

Fala-se também do alto índice de reprovação nos cursos de engenharia e como se relaciona com a atitude docente:

Mas é uma coisa de praxe, muita gente reprova essa disciplina todo semestre e esse professor particularmente é desses que ficam orgulhosos; a taxa de reprovação das disciplinas é um tipo de status (para o professor), pra dizer que você é o fodão; foram muitas, quarenta pessoas reprovaram.

No grupo focal, os estudantes também falaram do estresse com notas e reprovação, e algumas atitudes de professores:

Ele (o professor) fala naturalmente que boa parte de vocês vai reprovar e eu fiquei tão pilhando com essas coisas. Teve a prova dele e foi uma coisa bem injusta. Era uma prova de 2 questões cada uma valendo 5 pontos e muita gente ficou muito nervosa e foi muito mal. Foi a nota mais baixa da minha vida e eu chorei, ele me viu chorando, mas aí foi um tanto surpreendente, não humilhou nem nada, falou que era só uma prova, não tinha por que ficar desse jeito. E no dia seguinte na aula ele me chamou para conversar e disse que a vida profissional infelizmente é assim e você tinha que se acostumar (ALUNO 2).

Às vezes a gente ta numa turma de uma cadeira anual, e chega uma época que ninguém mais se suporta, é uma briga, é um estresse, e eu vivo isso quase todo dia, é um problema que vivo (ALUNA 9).

A aluna 8 aponta um dos problemas geradores de estresse:

E tem também a questão dos horários; você não consegue montar um cronograma, uma rotina. Como nosso departamento, que tem oito professores, eles não conseguem fechar um horário bom. E a pessoa fica a mercê, por isso que as pessoas vão para as particulares, porque tem os horários que as pessoas querem. Faculdade pública tem esse problema. Você tem que ter todo o dia disponível pra estudar. 
Os resultados que surgiram da análise temática dos dados estão expressos nas categorias apresentadas como "NÓS", com suporte nos relatos dos sujeitos da pesquisa, a técnica "nuvens de palavras" do Nvivo, que pode ser compreendida como uma maneira de visualização de dados linguísticos. Assim, expomos as categorias de "NÓS” utilizadas nesta análise.

A Figura 1 mostra os sentimentos dos alunos provocados pelo estresse advindo das atitudes dos professores com relação às notas, às provas, prazos, que se manifesta pela ansiedade, receio de reprovação, pelo abuso moral.

Figura 1 - Nuvem de palavras frequentes utilizando os nós "notas", "reprovação" e "estresse"

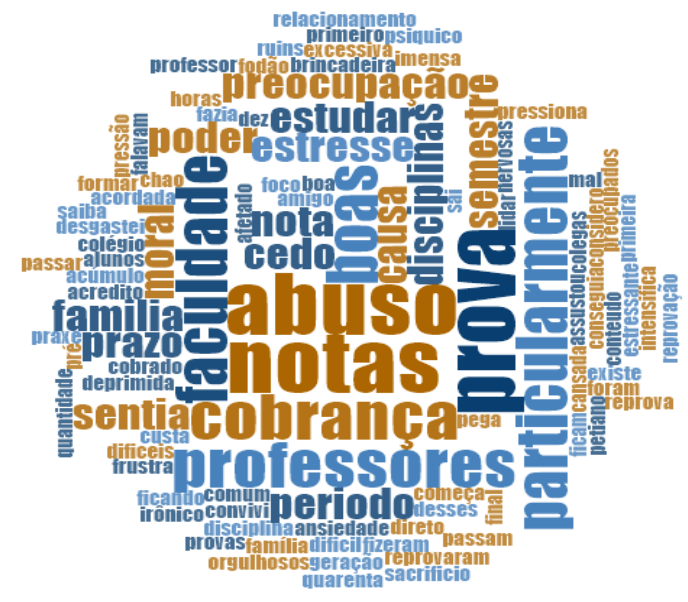

Fonte: NVivo 10

A Figura 1 mostra que palavras como "abuso", "cobrança", "notas" e "provas", além de "professores", foram as mais frequentes quando foram considerados os nós "notas", "reprovação" e "estresse".

\section{Categoria 2 - ensino e relação com professor:}

Apreende-se com o discurso dos alunos que o processo de ensino engendrado pelos professores envolve dois aspectos: a didática do docente e a forma como o ele se relaciona interpessoalmente com os estudantes:

Você está estudando uma coisa complicadíssima, uma equação enorme, e você vê poucas aplicações reais daquilo; o que ele te avalia é a modelagem matemática precisa e não a tua aptidão de resolver um problema real; especificamente pelo método de ensino da engenharia eu acho erradíssimo. E que é pessoal, vem de cada professor a relação aluno-professor; o grande problema nesse sentido é que quem dá o curso é o pessoal da matemática, que são doutores, tem uma formação muito boa no nível acadêmico, mas muitas vezes não são didáticos ou então não aplica pra engenharia.

Há preocupação também com um dos tripés da universidade, além do ensino, que é a pesquisa: "é um professor para sete, oito alunos, o professor também fica sobrecarregado. O aluno fica solto e não produz nada, chega ao fim do semestre e da bolsa e não tem muita coisa, fica uma pesquisa vazia".

Os alunos apontam os pontos positivos que há no ensino daquelas faculdades:

Alguns professores são excelentes porque eles focam, cobram realmente o que a gente vai usar, mas outros cobram o que a gente não vai usar; no meu curso, de forma geral os professores são bons; tem professores mais novos que incentivam que o procurem na sala dele que eles querem que os alunos estejam bem. 
E sugerem-se dinâmicas de grupo e empresa Júnior como formas adequadas de aprendizado. No grupo focal, a aluna 7 comenta que:

Eu faço engenharia de petróleo, as turmas são bastante reduzidas, então essa relação professor-aluno ela fica bem mais próxima, tanto eu quanto meus colegas têm uma aproximação muito grande com os professores. Isso eu também percebi fazendo cadeiras do curso de engenharia química, onde tem muitos mais alunos por turma, que a gente tem uma relação mais fraca com o professor ou às vezes não tem. É diferente das turmas reduzidas. O professor ta sempre acompanhando o desempenho do aluno, sabe pelo nome.

A aluna 6 confirmou essa questão:

Desde que eu entrei no curso de engenharia química, eu sempre percebi que a nossa relação com professores, com a coordenação, com o grupo gestor é muito pontual. A nossa relação com quem nos ensina é muito vaga, muito pequena. Eles são extremamente carrascos, gostam de mostrar que tem poder.

A aluna 6 comentou a satisfação com a proximidade de alguns professores:

Quando você vê um professor diferente, chega você se enche. Eu tenho uma cadeira este ano que é específica do meu curso e ele é bem mais próximo da gente. É uma raridade, ele é uma raridade. Ele tem grupo de whatsapp com a gente, pergunta como a gente ta se saindo, ele diz que está preocupado com nossas notas, com nossas faltas, ele conversa com a gente.

Quanto a metodologias de ensino, a aluna 6 comentou:

Ele (o professor) tem a metodologia sala invertida, que é muito boa, que até uns aqui usam na faculdade, dá muito certo pelo menos pra mim; tem outros professores que tem a didática boa. Tem um professor de uma cadeira com 70 alunos, mas a didática é tão boa, não é carrasco e não coloca medo na gente, de uma forma tão eficaz que eu, e eu não gosto da disciplina dele, consegui absorver coisas que eu nunca pensei que ia absorver.

Na Figura 2, as palavras "professor" e "professores" destacam-se, enquanto "aluno" e "aprendizado" não estão em destaque. Pode-se compreender que, na relação professor-aluno nos cursos de engenharia do CT-UFC, o estudante fica em segundo plano, assim como o processo de ensino-aprendizagem. A relação professor-aluno nas IES é construída na rotina das instituições. Há sempre um contrato didático que media essa relação. Destaca-se também que professores e alunos criam expectativas acerca do que esperam do comportamento do outro (Roncaglio, 2004).

O Estudo Melo Junior et al. (2020) sobre a percepção dos estudantes de engenharia acerca da didática e metodologia empregadas por docente de engenharia na região Centro-Oeste do Brasil, apontou que estes cursos precisam mudar o método de ensino, tanto em relação a metodologias ativas quanto no domínio da didática.

Ademais, por meio do relato dos alunos, parece que professores se esquecem de que, para além da transmissão objetiva de conhecimentos teóricos e técnicos de disciplinas, são responsáveis pelo processo de construção de sujeitos por meio da construção dialógica de aspectos socioculturais. (Roncaglio, 2004).

A elevada taxa de transtornos mentais comum entre estudantes de Engenharia, ligada a fatores pessoais, psicoemocionais e ao ensino-aprendizagem, justifica atenção direcionada aos processos de ensino-aprendizagem, usada nestes cursos de Engenharia e necessidade urgente de acompanhamento da saúde mental desses estudantes. (Dantas, 2020). 
A Figura 2, as palavras "professor" e "professores" destacam-se, enquanto "aluno" e "aprendizado" não. Pode-se compreender que, na relação professor-aluno nos cursos de engenharia do CT-UFC, o estudante fica em segundo plano, assim como o processo de ensino-aprendizagem.

Figura 2 - Nuvem de palavras frequentes utilizando os nós "ensino" e "relação com professor".

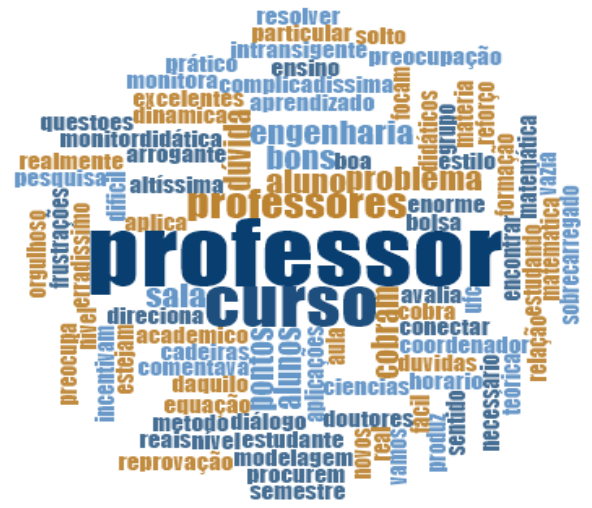

Fonte: NVivo 10 .

As falas dos alunos acerca da aprendizagem e relacionamento com professores apontam que o processo ensinoaprendizagem depende da didática do professor e do seu relacionamento com os alunos, que muitos docentes transmitem muitos conhecimentos, mas não tem didática, questionam a utilidade dos conhecimentos transmitidos, poucos professores para muitos alunos.

Na figura acima, as palavras "professor" e "professores" destacam-se, enquanto "aluno" e "aprendizado" não estão em destaque. Pode-se compreender que, na relação professor-aluno nos cursos de engenharia do CT-UFC, o estudante fica em segundo plano, assim como o processo de ensino-aprendizagem.

\section{Categoria 3 - saúde mental, desistência, suporte e suporte externo}

Nessa categoria, percebeu-se que há relação da saúde mental que se encontra o aluno para pensar em desistir da faculdade em curso. Alguns apontamentos dos entrevistados mostraram como a desistência é uma possibilidade comumente avaliada por eles: "quase desisto da faculdade; nunca pensei em desistir de fato do curso de engenharia, mas passou rapidamente durante um ou dois semestres; tou pensando em deixar o curso". Pode também interferir com a decisão no futuro: "já fiquei muito desestimulado a ponto de não saber se eu vou trabalhar com engenharia no futuro".

Nove entre os 12 alunos do grupo focal responderam que pensaram em desistir do curso.

A aluna 12 comentou que:

Desde que eи entrei, todo semestre eи falo que eи vou sair, todo semestre, tanto que ano passado eu tentei transferência de curso interna, e não deu certo; e eu disse pra mim mesma, você vai tentar transferência de curso, não consegue então você vai ate o fim do jeito que tiver. Tanto que neste ano não fiz inscrição pro Enem (Exame Nacional do Ensino Médio). Todo ano eu fazia, desde que entrei aqui continuei fazendo.

Quanto à saúde mental, os entrevistados descrevem tanto como se manifestam suas emoções, quanto os sintomas clínicos de depressão e transtornos de ansiedade:

Considero que a minha saúde mental mudou muito desde que entrei, desde o periodo da escola até a faculdade; Eu tenho ansiedade, já fiz tratamento; Síndrome do pensamento acelerado e ansiedade; Não percebi que a faculdade 
atingia minha saúde mental; Insônia; perdendo horas de sono; Conheço gente que já passou por isso, quase que depressivo; Acho que quem passa por isso esconde muito, quer passar a impressão que está tudo bem.

A aluna 9 do grupo focal fez um apanhado de como seu sono e seu cansaço foi se desenvolvendo e afetando sua saúde psíquica:

Porque eu tenho bolsa e as cadeiras são em horários quebrados, então tenho que passar o dia inteiro. E isso me causa muito cansaço mental, é como se eu não dormisse, porque chego em casa 8 h e tenho coisas pra fazer ainda e quando durmo é como se ficasse aquela sensação que eu não dormi. Todo lugar que eu vou eu tento dormir, se eu me encostar eu durmo, porque eu fico estressada pelo sono acumulado. E isso me causou irritação e que qualquer coisa eu explodisse, e às vezes com o conteúdo, isso só faz piorar.

E como isso afetou as relações interpessoais:

O professor não sabe que naquele dia, o que você fez pra estar ali, e ate mesmo os colegas não sabem, e você acaba se isolando, não sabendo como agir, entendeu? E as pessoas às vezes não entendem. Então eu tenho esse problema atualmente e acredito que não só eu que moro longe, mas pessoas que moram perto também sofrem isso. E eu vejo muito isso aqui no CT.

A aluna 8 relatou, chorando, que:

Justamente nos semestres mais críticos que eu tive, terceiro, quinto, sétimo, eu tinha muito problema pra dormir, eu acordava pensando no cálculo que eu tinha feito errado na prova ou então dormia e acordava com paralisia do sono, pra mim especialmente isso foi muito marcante, a sensação de quase morrer, de ser perseguida, não gosto nem de lembrar.

Ela descreveu de forma ainda mais preocupante essa experiência de sofrimento psíquico.

Não vale a pena sacrificar o meu tempo de sono porque eu não rendo, eu não aprendo; eu tive vários distúrbios do sono, depressão, mas não como amigos que já atentaram contra a própria vida. (Eles fizeram isso) não especificamente por causa da faculdade, foi só um aditivo, mas acho que a faculdade contribui para o mal estar psíquico. No semestre passado, percebi que virei uma pessoa amarga e não vejo esperança em nada na vida; talvez seja depressão, não sei.

Problemas de saúde psíquica no que tange a quadros de transtornos de ansiedade e depressivos são os principais motivos de buscar-se por auxílio profissional nos campi universitários. A ansiedade, contudo, pode ter um processo de adaptação, uma vez que o ambiente universitário gera novos receios, principalmente na transição do ensino médio para a graduação. A ansiedade patológica, por outro lado, leva a prejuízos no funcionamento psicossocial e cognitivo, dificultando a progressão do aprendizado necessária ao desempenho acadêmico esperado. (American Psychiatric Association, 2014; Sarriera et al., 2012).

Quanto ao suporte dentro do ambiente acadêmico, a informação transmitida somente é percebida pelos colegas universitários.

Institucionalmente eu não recebo suporte nenhum da UFC; ninguém fala essas coisas pra gente, ninguém dá uma dica; sei que existem psicólogos da UFC, mas não soube pela UFC, eu soube pelo facebook, mas não foi a minha coordenação que postou; coordenação não ajuda em nada, é pra assuntos burocráticos, não de solução de problemas pessoais de alunos; eu já vi gente que foi falar com professor, ele só disse que não podia fazer nada; de apoio 
psicológico concreto da instituição, nada; em sala de aula, os professores não dão suporte; acho que ao todo só uns três professores fazem isso; tem palestras sobre saúde mental por conta do setembro amarelo; os alunos mesmo se mobilizam por atividade do CA (centro acadêmico), ou outras entidades, como empresa júnior.

A aluna 7 faz um contraponto sobre a ajuda de seus colegas: "ao mesmo tempo que tem muito colega que passa o que a gente sente, tem colegas que se trancam, acham que não devem demonstrar fraqueza ou não entendem mesmo o que você ta passando".

Na Figura 3, as expressões "saúde mental" e "professores" estão em destaque, além de "suporte" e "faculdade". Podese entender, considerando também as falas dos alunos, que se espera do corpo docente um apoio mais próximo para as demandas emocionais que surgem no decorrer da graduação.

Figura 3 - Nuvem de palavras frequentes utilizando os nós "saúde mental", "desistência", "suporte" e "suporte externo"

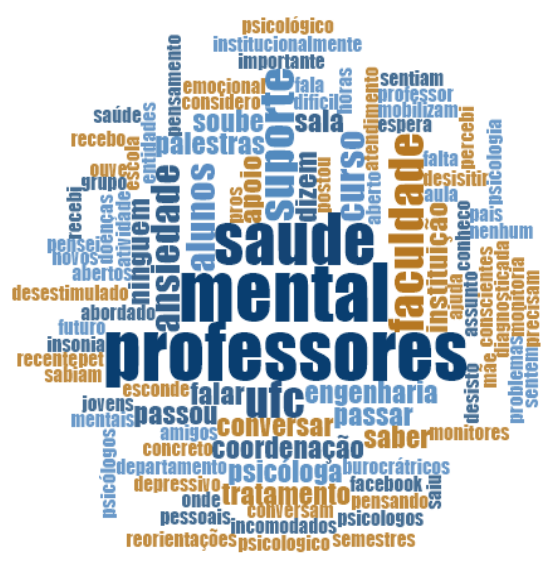

Fonte: NVivo 10.

O suporte externo, ou seja, da família, por outro lado, é citado: "Apoio pessoal dos meus pais eu recebi muito, muito mesmo; minha mãe foi a pessoa que sempre me apoiou ". $\mathrm{O}$ aluno 3 relatou que:

Por parte da família não recebo nenhuma cobrança, eles são meus pontos fortes, se acontece alguma coisa comigo eles estão lá pra me ajudar; eu sou do Piauí, então semana sim, semana não, eu vou pra lá pra visitar eles, e eu tou morando aqui sozinho e é difícil pra mim. Uma frase que minha mãe sempre diz é que se você quiser voltar nós estamos de braços abertos.

A família é a fonte de suporte mais importante aos estudantes universitários, tanto afetivo e emocional, como material e de orientação para lidar com as dificuldades que surgem (Baptista, Souza \& Alves, 2008).

\section{Categoria 4 - ser estudante de engenharia}

Os estudantes de engenharia do CT-UFC descrevem como se sentem nesse papel, e abordam uma questão que já consideram cultural na universidade.

Até porque é uma coisa meio inserida na cultura do estudante de tecnologia de que pra passar na faculdade de tecnologia você tem que se dar mal, você tem que sair com essas cicatrizes mentais; essa cultura de sofrimento é estabelecida dentro do estereótipo do estudante de engenharia, que tem de sofrer na mão de professor; pra ser engenheiro, tem que sofrer; a engenharia, a gente já sabe que vai ser difícil; escola, família, sabe que engenharia de forma geral comparada com outros cursos é um curso mais pesado. 
A aluna 10 no grupo focal comenta, sobre esse assunto: "muitas pessoas não sabem a realidade que a gente tem aqui ". A aluna 8 comentou:

Que acho que essa questão da superioridade fica mais na sociedade quando você fala que é estudante de engenharia, aí, ah meu Deus, mas não tem nada demais. Mas gera uma autocobrança como se você fosse alguma coisa a mais.

O aluno 3, por sua vez, observou: "eu nem gosto de falar que eu faço engenharia".

A Figura 4 apresenta, as palavras "professor" e "professores" destacados, podendo significar que os estudantes de engenharia vivenciam a importância de seus mestres também no objetivo de formarem-se engenheiros.

Figura 4 - Nuvem de palavras frequentes utilizando o nó "ser estudante de engenharia"

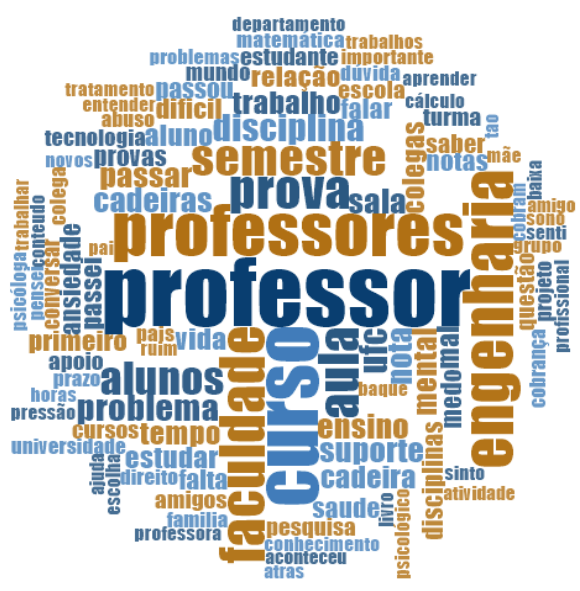

Fonte: NVivo 10.

Por mais que esses sujeitos tenham falado do mal-estar na relação com professores e não com coordenadores, é preciso lembrar que a qualidade da relação não depende apenas dos professores e dos alunos, mas, também, da mediação dos coordenadores.

Assim, pode-se dizer que, se há conflitos de um professor com alunos, coordenadores e diretores de departamentos, entre outros atores desse cenário, também são responsáveis por esse mal-estar.

Considerando os relatos dos sujeitos da pesquisa, pergunta-se: será que esses professores que são, de acordo com as narrativas, repressores, também não estão passando por problemas psíquicos? Portanto, outra questão se apresenta: será que seus superiores na instituição, como coordenadores e diretores, estão cuidando desses professores? É preciso refletir de forma complexa, pois a universidade é um cenário múltiplo, logo, diante desses conflitos, todos esses atores devem corresponsabilizar-se pelo mal-estar na relação professor-aluno e juntos buscarem soluções adequadas.

\section{Considerações Finais}

É premente que as coordenações de graduações e a direção de departamento se preocupem com a saúde mental de seus alunos desde sua entrada na universidade, promovendo ações preventivas no âmbito das IES. Incluem-se entre essas ações a organização de projetos pedagógicos que não levem os estudantes a excessos de atividades irrelevantes ao processo de ensino e aprendizagem e métodos avaliativos adequados a esse processo, que procurem pautar-se em metodologias ativas, comprovadamente mais eficazes. Os currículos dos cursos de Engenharia de IES podem ser pensados de maneira a garantir momentos de descanso para o aluno e aulas em horários que respeitem as necessidades físiológicas do ser humano, como tempos de sono e alimentação suficientes. 
Ademais, é necessário o estímulo à formação de núcleos de acompanhamento pedagógico em todos os cursos de graduação que tiveram sujeitos participantes dessa pesquisa, a fim de acompanhar o desenvolvimento da aprendizagem ao longo do curso, incluindo o possível surgimento de sofrimentos relacionados com a universidade ou que atrapalhem os ganhos acadêmicos de cada um. Para pessoas que acabem manifestando algum sofrimento psíquico maior e mesmo psicopatologias, deve haver meios de acolhimento de profissionais de saúde capacitados, e o correto direcionamento a estes serviços.

Competem, também, às direções e coordenações de graduações capacitarem os professores a identificarem alunos em sofrimento psíquico, além de promover educação continuada em recursos pedagógicos, como o uso de novas metodologias de ensino-aprendizagem, como as chamadas metodologias ativas. Mas o corpo docente, também, precisa se corresponsabilizar em buscar esse conhecimento, cobrando das IES o espaço para que essa problemática seja remediada.

\section{Referências}

American Psychiatric Association (2014). Manual diagnóstico e estatístico de transtornos mentais: DSM-5. (5a ed).

Assis, A. D. \& Oliveira, A. G. B. (2010). Vida universitária e saúde mental: atendimento às demandas de saúde e saúde mental de estudantes de uma universidade brasileira. Caderno Brasileiro de Saúde Mental, 2(5), 159-177.

Baptista, M. N., Souza, M. S. \& Alves, G. A. S. (2008). Evidências de validade entre a escala de depressão (EDEP), o BDI e o Inventário de Percepção de Suporte Familiar (IPSF). Psico-USF, 13 (2), 211-220 http://pepsic.bvsalud.org/pdf/psicousf/v13n2/v13n2a08.pdf

Bardin, L. (2010). Análise de conteúdo. Edições 70.

Bertol, C. E. \& Souza, M. de (2010). Transgressões e adolescência: individualismo, autonomia e representações identitárias. Psicol. Ciência e Profissão, 30 (4), 824-839 http://www.scielo.br/scielo.php?script=sci_arttext\&pid=S1414-98932010000400012\&lng=pt\&tlng=pt.

Brasil. (2012). Ministério da Saúde. Conselho Nacional de Saúde. Resolução n. ${ }^{4} 466$, de 12 de dezembro de 2012 . Aprovações normativas de pesquisas relacionadas a seres humanos. Ministério da Saúde. https://bvsms.saude.gov.br/bvs/saudelegis/cns/2013/res0466_12_12_2012.html.

Castro, V. R. (2017). Reflexões sobre a saúde mental do estudante universitário: estudo empírico com estudantes de uma instituição pública de ensino superior. Rev. Gestão em Foco, 9, 380-401 https://portal.unisepe.com.br/unifia/wp-content/uploads/sites/10001/2018/06/043_saude_mental.pdf

Dantas, I. L.; Matos, D. L.; Moreira, J. J. S; Melo, E. V.; Costa, E. F. O., \& Leite Neta, M. T. S. (2021). Relação entre saúde mental e vivência acadêmica dos estudantes de Engenharia de Alimentos e Engenharia Civil de uma universidade pública da região Nordeste. Research, Society and Development, 10, e48910313585-14.

Flach, L. (2009). Sofrimento psíquico no trabalho contemporâneo: analisando uma revista de negócios. Psicol. soc, 21 (2), $193-202$.

Lage, M. C. (2010). Utilização do software NVivo em pesquisa qualitativa: uma experiência em EaD. ETD - Educação Temática Digital, 12, 198-226. https://doi.org/10.20396/etd.v12i0.1210

Lobato, C. R. P. S. (2004). O significado do trabalho para o adulto jovem no mundo do provisório. Rev. psicol. UnC, 1 (2), $44-53$.

Melo Júnior, G. de; Oliveira Filho, R. M. de; Vieira, S. L.; Macedo, S. O. de; Furriel, G. P.; Silva, B. C. R., \& Naves, J. S. (2020). Análise do ensino de Engenharia no Brasil: estudo de caso na região Centro-Oeste. Research, Society and Development, 9 , e179119517.

Minayo, M. C. S. (1993). Pesquisa social teoria, método e criatividade Rio de Janeiro: Vozes.

Moro, A., Valle, J. B. do \& Lima, L. P. de (2005). Sintomas depressivos nos estudantes de Medicina da Universidade da Região de Joinville (SC). Rev. Bras. Educ. Med, 29(2), 97-102 http://www.scielo.br/scielo.php?script=sci_arttext\&pid=S0100-55022005000200097\&tlng=pt

Nogueira, M. J. C. (2017). Saúde mental em estudantes do ensino superior: fatores protetores e fatores de vulnerabilidade. Lisboa. Tese de doutorado, Universidade de Lisboa, Portugal.

Pope, C. \& Mays, N. (2000). Qualitative research in health care. (2a ed.). BMJ Books.

Roncaglio, S. M. (2004). A relação professor-aluno na educação superior: a influência da gestão educacional. Psicol. Ciência e Profissão, 24 (2), 100-111 http://www.scielo.br/scielo.php?script=sci_arttext\&pid=S1414-98932004000200011\&lng=pt\&tlng=pt

Sampaio, S. M. R. (2011). Observatório da vida estudantil: primeiros estudos. EDUFBA.

Sarriera, J. C., Paradiso, Â. C., Schütz, F. F. \& Howes G. P. (2012). Estudo comparativo da integração ao contexto universitário entre estudantes de diferentes instituições. Rev. Bras, 13 (2),163-172 http://pepsic.bvsalud.org/pdf/rbop/v13n2/04.pdf

Silveira, C., Norton, A., Brandão, I. \& Roma-Torres, A. (2011). Saúde mental em estudantes do ensino superior experiência da consulta de Psiquiatria do Centro Hospitalar São João. Acta Med Port, 24 (2), 247-256.

Sousa, N. A. \& Marques, I. R. (2010). Período de estudos e qualidade de vida do estudante de enfermagem. Rev. bras. qual. vida, 2 (2), 1-8.

Sousa, T. F. de, José, H. P. M. \& Barbosa, A. R. (2013) Risk behaviors to health in Brazilian college students [Condutas negativas à saúde em estudantes universitários brasileiros]. Cienc. e Saude Coletiva, $18 \quad$ (12), 3563-3575 http://www.scopus.com/inward/record.url?eid=2-s2.084888158719\&partnerID=40\&md5=96f6e 074c8bfeadb1921 aca09f79992b. 